\title{
Evaluation of the flux gradient technique for measurement of ozone surface fluxes over snowpack at Summit, Greenland
}

\author{
F. Bocquet ${ }^{1, *}$, D. Helmig ${ }^{1}$, B. A. Van Dam ${ }^{1}$, and C. W. Fairall ${ }^{2}$ \\ ${ }^{1}$ Institute of Arctic and Alpine Research, University of Colorado at Boulder, UCB 450, Boulder, CO 80309, USA \\ ${ }^{2}$ Earth System Research Laboratory, NOAA, Boulder, Colorado USA, 325 Broadway, Boulder, CO 80305, USA \\ *now at: Cooperative Institute for Research in Environmental Sciences, University of Colorado at Boulder, UCB 216, \\ Boulder, CO 80309, USA
}

Received: 19 January 2011 - Published in Atmos. Meas. Tech. Discuss.: 14 February 2011

Revised: 19 September 2011 - Accepted: 26 September 2011 - Published: 25 October 2011

\begin{abstract}
A multi-step procedure for investigating ozone surface fluxes over polar snow by the tower gradient method was developed and evaluated. These measurements were then used to obtain five months (April-August 2004) of turbulent ozone flux data at the Summit research camp located in the center of the Greenland ice shield. Turbulent fluxes were determined by the gradient method incorporating tower measurements of (a) ozone gradients measured by commercial ultraviolet absorption analyzers, (b) ambient temperature gradients using aspirated thermocouple sensors, and (c) wind speed gradients determined by cup anemometers. All gradient instruments were regularly intercompared by bringing sensors or inlets to the same measurement height. The developed protocol resulted in an uncertainty on the order of $0.1 \mathrm{ppbv}$ for 30-min averaged ozone gradients that were used for the ozone flux calculations. This protocol facilitated a lower sensitivity threshold for the ozone flux determination of $\sim 8 \times 10^{-3} \mu \mathrm{g} \mathrm{m}^{-2} \mathrm{~s}^{-1}$, respectively $\sim 0.01 \mathrm{~cm} \mathrm{~s}^{-1}$ for the ozone deposition velocity for typical environmental conditions encountered at Summit. Uncertainty in the 30-min ozone exchange measurements (evaluated by the Monte Carlo statistical approach) was on the order of $10^{-2} \mathrm{~cm} \mathrm{~s}^{-1}$. This uncertainty typically accounted to $\sim 20-100 \%$ of the ozone exchange velocities that were determined. These measurements are among the most sensitive
\end{abstract}

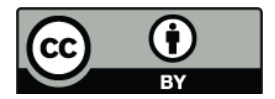

Correspondence to: D. Helmig (detlev.helmig@ colorado.edu) ozone deposition determinations reported to date. This flux experiment allowed for measurements of the relatively low ozone uptake rates encountered for polar snow, and thereby the study of their environmental and spring-versus-summer dependencies.

\section{Introduction}

Gas flux to the surface is commonly described by an analogy to electrical resistances taking into account physical and chemical processes affecting the flux. In chemical transport models (e.g., MOZART, ECHAM, IMPACT), chemical interactions of ozone with the surfaces (e.g., snow, ice, sea-ice) are typically represented by a surface resistance $\left(R=v_{\mathrm{d}}^{-1}\right.$, $v_{\mathrm{d}}=$ deposition velocity). For snow, an ozone surface resistance value of $2000 \mathrm{~s} \mathrm{~m}^{-1}$ is commonly used, and this value is kept constant throughout the day and the year (Ganzeveld and Lelieveld, 1995; Rotman et al., 2004; Lamarque et al., 2005). Ozone fluxes over snow are linked to chemical interactions in the snowpack. Ozone in the polar snowpack has been found to undergo depletion, which follows both the diurnal and seasonal cycle in solar radiation (Helmig et al., 2007a). These observations suggest that ozone surface fluxes should vary similarly with time of day and season. Accurate measurements of ozone surface exchanges would provide a means for evaluating the net effect of ozone snow photochemical processes on boundary-layer ozone. Previous

Published by Copernicus Publications on behalf of the European Geosciences Union. 
ozone flux measurements over polar snow have not been able to demonstrate this behavior, likely due to the lack of measurement sensitivity and required long-term observations. Several studies have demonstrated approaches for determining fluxes at the snow surface from concentration gradient measurements inside the snowpack (e.g., Seok et al., 2009; Helmig et al., 2009a, c). These calculations are based on gas diffusion theory and require determination of chemical gradients and the snowpack density for estimating of the gas diffusivity inside the snowpack. To date, this method has primarily been applied for conditions where there is gas transfer from the underlying substrate to the snow surface. For ozone flux determination another complicating factor is that there is a flux divergence within the gradient interval, as ozone is chemically lost in the upper snow layers.

Regener (1957), Galbally (1968), and Aldaz (1969) were among the first researchers to study ozone uptake to the Earth's surface. A review of atmosphere-surface exchange measurement techniques used in the subsequent $20 \mathrm{yr}$ was given by Dabberdt et al. (1993). Table 1 in the Supplement provides a summary of experimental ozone flux techniques from our review of more than 120 published papers on ozone deposition and gas exchange. Ozone deposition results span a wide range. The largest ozone exchange velocities (ozone $v_{\mathrm{e}}$; please note that in this paper we will use the notation of "ozone exchange velocity", rather than "ozone deposition velocity", to avoid use of negative velocity values), on the order of $2 \mathrm{~cm} \mathrm{~s}^{-1}$ have been measured over vegetation. In comparison, snow and water appear to be the most inert surfaces towards ozone.

The overview in the Supplement also lists the different types of experimental methods, their application areas, and measured rates of ozone surface deposition/exchange. Eddy covariance is the most popular flux method $(\sim 65 \%)$, followed by the profile/tower gradient method $(\sim 26 \%)$, and studies relying on the box/chamber method $(\sim 9 \%)$.

Previous ozone flux measurements over snow have been conducted using an array of different techniques. Few of these studies provided detailed characterization of the sensitivity of the flux measurement. Galbally and Allison (1972) were the first ones who measured ozone fluxes over old and fresh snow surfaces at Mt Buller, Australia, and at Mawson, Antarctica. These authors determined vertical ozone gradients using a modified Ehmert potassium iodide ozone sensor. Estimated errors in the concentration measurement for the flux determination were reported to be on the order of \pm 1 ppbv (Galbally and Allison, 1972). Later on, Colbeck and Harrison (1985) estimated that "errors in determining individual ozone deposition velocities [to seasonal snow over grassland] are around $30 \%$, the largest contribution to the error being due to the standard error in ozone gradient." The ozone monitor used in the Colbeck and Harrison (1985) study was a chemiluminescence sensor using ethylene as the reactant and was reported to have a measurement precision of \pm 1 ppbv. An eddy correlation-based method using a $15-\mathrm{Hz}$ chemiluminescence ozone monitor reacting with eosin-y was used to measure ozone fluxes over seasonal snow at a subalpine forest site. There was no mentioning of the precision for this measurement (Stocker et al., 1995; Zeller and Hehn, 1996; Zeller and Nikolov, 2000).

While there is a large scatter in measured ozone $v_{\mathrm{e}}$, particularly over snow, a majority of the flux measurement results fall within the range of $0.01-0.1 \mathrm{~cm} \mathrm{~s}^{-1}$ (Helmig et al., 2007b). Despite this relatively low surface uptake rate, ozone deposition to polar snow is an important ozone sink because other chemical processes that determine the ozone budget are weak compared to other environments (Helmig et al., 2007b).

In this paper we present research aimed at characterizing and improving the sensitivity of ozone flux determination by the gradient method, also known as the gradient profile method, and results from field measurements of ozone exchange over the polar snow at Summit, Greenland. The challenge of flux gradient measurements is to conduct highly accurate and precise measurement of gradients that are small (on the order of tenths of ppbv for ozone, and tenths of ${ }^{\circ} \mathrm{C}$ and $\mathrm{m} \mathrm{s}^{-1}$ for temperature and wind speed, respectively) in relation to the absolute magnitude signal of the measured variable. This requirement is particularly critical for resolving the anticipated small vertical ozone gradients. Therefore, a considerable amount of effort was dedicated towards the characterization and optimization of the instrument performance.

\section{Study site and measurements}

These flux experiments were performed at the Summit Environmental Observatory, in the dry-snow zone of the Greenland ice sheet $\left(72^{\circ} 34^{\prime} \mathrm{N}, 38^{\circ} 29^{\prime} \mathrm{W}\right.$, elevation $\left.3208 \mathrm{~m}\right)$, during 22 March-14 August 2004 (day of the year (DOY) 82227). The surface surrounding the site is smooth with average surface slopes typically less than $0.005^{\circ}$. The relatively flat area at Summit provides a homogenous fetch in all directions, which makes it an excellent site for tower-based flux measurements.

The 12-m flux tower was located $\sim 250 \mathrm{~m}$ south (upwind) of the camp buildings in the "Clean Air Sector". Ozone, air temperature, and wind speed were measured at three heights of 0.75, 2 and $10 \mathrm{~m}$ (Fig. 1; also see Fig. 1 in Helmig et al., 2007a for a schematic diagram of the Summit Flux Facility). Note that the actual sampling heights changed over the course of the study due to the accumulation of new snow. The change in the sensor height was monitored with an ultra-sonic distance sensor (model LI-200X, LI-COR Biosciences, Lincoln, NE). Air temperature was measured by type $\mathrm{E}$ thermocouple wires mounted into aspirated radiation shields (model 43408, R. M. Young, Traverse City, MI). Temperature gradients were determined directly by wiring thermocouples from two adjacent measurement heights in series. Wind speed was measured with cup anemometers (model 010C, Met One Instruments, Grants Pass, OR). These 


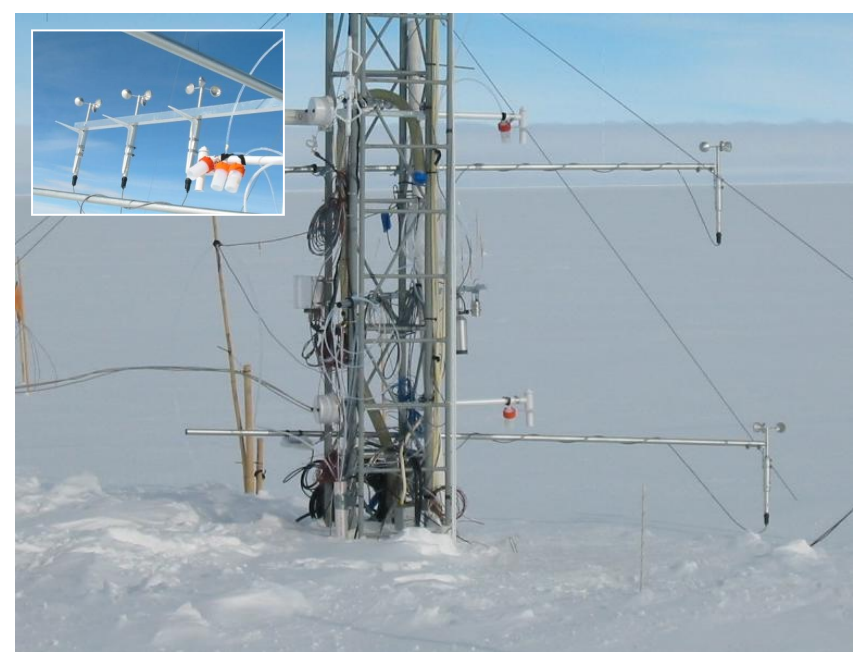

Fig. 1. Photograph showing the setup of the ozone flux gradient experiment on the Summit flux tower. The picture depicts the two lowest measurement heights $(2 \mathrm{~m}, 0.75 \mathrm{~m})$ only. Instruments are pointing towards the south, the dominating wind direction at Summit. Each gradient height measurement consists of a wind speed measurement (located furthest to the right in the picture, supported by the cross arm, a temperature measurement, with a downwards pointing inlet from the aspirator, and an ozone inlet funnel (in orange). The insert in the upper left corner shows the cup anemometer and ozone inlet arrangement during an inter-comparison experiment.

sensors were mounted on cross arms pointing south of the tower, into the dominating wind direction. Incoming and reflected solar radiation were recorded by two pyranometers (model LiCor 200X, Campbell Scientific Instruments, Logan, UT). Wind speed and temperature sensors were subjected to inter-comparison calibrations on three occasions during the study (beginning, middle and end of the experiment) and correction functions were determined from the inter-comparison measurements and applied to all data. Details on the ozone measurements are provided in Sect. 3.2.

A brief overview of environmental conditions encountered at Summit during the field period is presented in Fig. 2. Air temperature (at $2 \mathrm{~m}$ height) (Fig. 2a) increased quite significantly during the campaign, from $\sim-45^{\circ} \mathrm{C}$ in spring to maxima of $\sim-5^{\circ} \mathrm{C}$ during late summer. Interestingly, the amplitude in diurnal temperature variation is larger during the spring (up to $\sim 30^{\circ} \mathrm{C}$ ) than during the summer $\left(\sim 20^{\circ} \mathrm{C}\right.$ ). Furthermore, the temperature gradient $(2-0.75 \mathrm{~m})$ shifted from being mostly positive (i.e., stable) to alternating between positive and negative on a diurnal basis (i.e., stable at night and unstable during daytime). This change in atmospheric stability from spring to summer is typical for this environment, and has been well documented (Cullen, 2003; Cohen et al., 2007). Wind speed (at $2 \mathrm{~m}$ height) (Fig. 2b) averaged around $4.6 \mathrm{~m} \mathrm{~s}^{-1}$ throughout the period, with increasing frequency of episodes with winds reaching $\sim 10 \mathrm{~m} \mathrm{~s}^{-1}$ as the summer approached. The solar radiation record (Fig. 2c) reflects the seasonal change in the solar zenith angle from spring to summer. At the beginning of the study period, incoming solar radiation ranged from $0-400 \mathrm{~W} \mathrm{~m}^{-2}$. Solar irradiance increased to a range of $50-700 \mathrm{~W} \mathrm{~m}^{-2}$ at the summer solstice. The net shortwave radiation (incoming minus reflected shortwave radiation) displays a similar behavior, with minimum values of $\sim 40 \mathrm{~W} \mathrm{~m}^{-2}$ at the beginning of the study, and maxima of $\sim 80 \mathrm{~W} \mathrm{~m}^{-2}$ around the summer solstice.

Surface ozone levels at Summit are remarkably high compared to other Arctic sites, typically falling within a range of 40-60 ppbv, with an annual median value of $47.5 \mathrm{ppbv}$. Two recent publications (Helmig et al., 2007b, c) that investigated the surface ozone behavior at Summit pointed out that the relatively high ozone concentrations are due to the elevation of Summit, the high frequency of ozone transport originating in the upper troposphere, and to occurrences of pollution transport events in the summer (Helmig et al., 2007c, d). Ozone mixing ratios during this measurement period (Fig. 2d) reflect this behavior, and varied from 30 to $60 \mathrm{ppbv}$, with occasional peaks up to $\sim 70 \mathrm{ppbv}$.

\section{Ozone flux gradient method}

\subsection{Gradient method}

The choice for using the tower gradient method was motivated by the availability of commercial sensors for all required measurements. The tower gradient method is based on the generally accepted micrometeorological similarity theory (i.e., diffusion coefficients for momentum, heat, water vapor and trace gases are assumed to be the same). The un-modified gradient method is only valid for neutral stability (for a Richardson number $R i$, of $0 \pm 0.01$ ), but empirical functions for near-unstable $(-0.1<R i<-0.01)$ and near-stable $(+0.01<R i<+0.1)$ conditions can be applied to extend the use of the method to a wider range of encountered atmospheric situations (Oke, 1987). In addition, the method requires steady state conditions over the averaging time and constant fluxes with height over the measurement interval.

Despite these requirements the method is relatively simple to use, as it involves measurements of wind speed, air temperature, and ozone mixing ratio at a minimum of two heights. In our case, measurements were conducted at three heights on the $12-\mathrm{m}$ tower, i.e., at $0.75,2$ and $10 \mathrm{~m}$. Ozone monitors record the ozone mixing ratio in unit of parts per billion volume (ppbv), which needs to be converted to an ozone mass per unit volume scale $\left(\mu \mathrm{g} \mathrm{m}^{-3}\right)$. This is done using the ideal gas law along with ambient temperature and pressure measurements.

The flux of an entity, e.g., ozone, is equated to the product of the concentration gradient of the entity and the eddy 
(a)

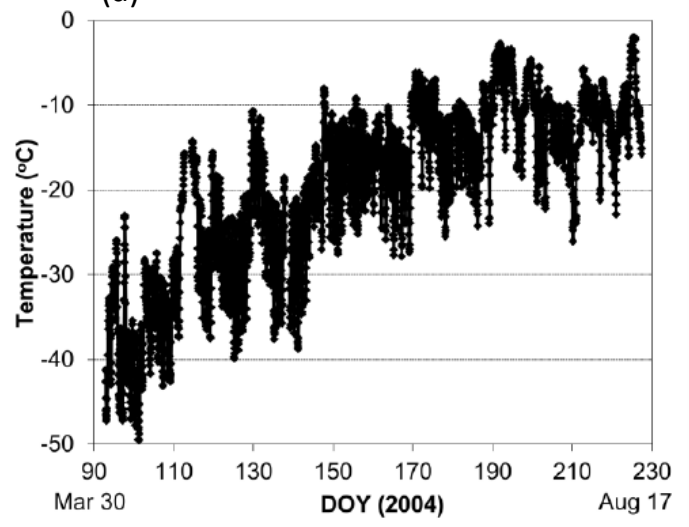

(c)

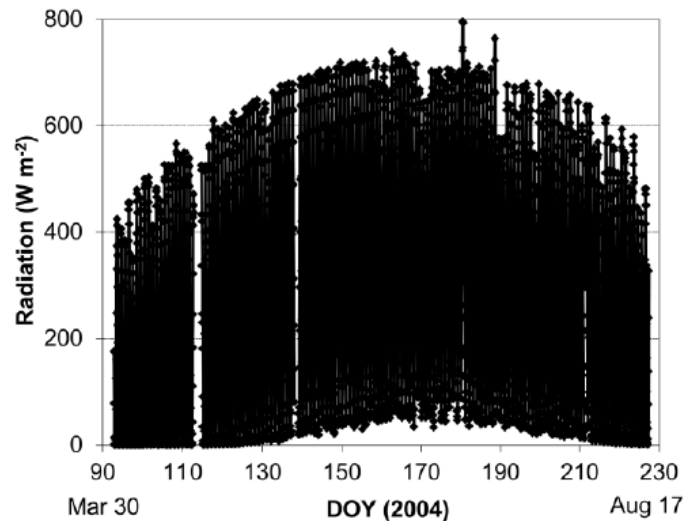

(b)

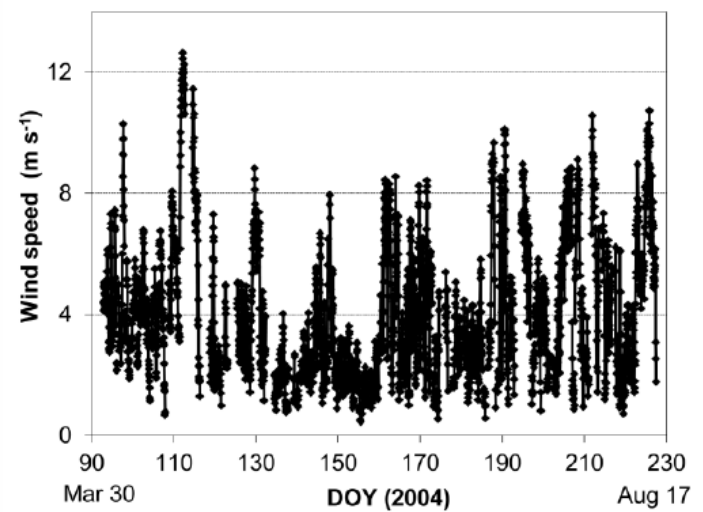

(d)

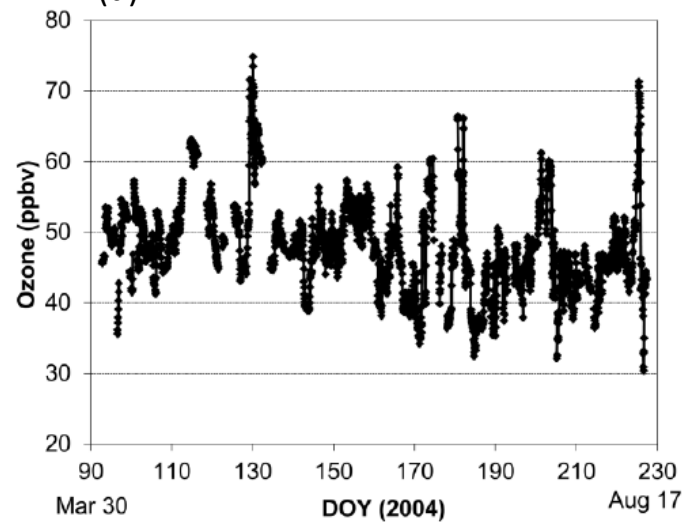

Fig. 2. Hourly averaged time series (DOY 92-227 [1 April-14 August 2004]) data for air temperature $\left({ }^{\circ} \mathrm{C}\right)(\mathbf{a})$, wind speed ( $\left.\mathrm{m} \mathrm{s}{ }^{-2}\right)(\mathbf{b})$, solar radiation $\left(\mathrm{W} \mathrm{m}^{-2}\right)(\mathbf{c})$, and ozone mixing ratio (ppbv) (d), each measured at $2 \mathrm{~m}$.

diffusivity function characterizing the atmosphere transporting that entity (Oke, 1987):

$F_{\mathrm{O}_{3}}=-k^{2} z_{\mathrm{r}}^{2}\left(\frac{\Delta \bar{u}}{\Delta z_{\mathrm{u}}} \cdot \frac{\Delta \overline{\mathrm{O}_{3}}}{\Delta z_{\mathrm{O}_{3}}}\right)$

where $k$ is the Von Karman constant $(=0.4), z_{\mathrm{r}}$ is the reference height (also known as logarithmic mean height), $z_{\mathrm{r}}=\left(z_{2}-\right.$ $\left.z_{1}\right) / \ln \left(z_{2} / z_{1}\right), \Delta \bar{u}$ and $\Delta \overline{\mathrm{O}_{3}}$ are the mean gradients of wind speed and ozone concentration, and $\Delta z_{\mathrm{u}}$ and $\Delta z_{\mathrm{O}_{3}}$ are the corresponding height gradients at which the wind speed or ozone measurements are taken, respectively.

As mentioned above, Oke (1987) introduced stability functions $\left(\Phi_{M} \Phi_{C}\right)^{-1}$ into Eq. (2), to allow for application of this flux method under a wider range of atmospheric conditions. Equation (2) then becomes:

$F_{\mathrm{O}_{3}}=-k^{2} z_{\mathrm{r}}^{2}\left(\frac{\Delta \bar{u}}{\Delta z_{\mathrm{u}}} \cdot \frac{\Delta \overline{\mathrm{O}_{3}}}{\Delta z_{\mathrm{O}_{3}}}\right)\left(\Phi_{\mathrm{M}} \Phi_{\mathrm{C}}\right)^{-1}$

where:

$\left(\Phi_{\mathrm{M}} \Phi_{\mathrm{C}}\right)^{-1}=(1-5 R i)^{2} ;$ for $R i>0$ (stable conditions)
$\left(\Phi_{\mathrm{M}} \Phi_{\mathrm{C}}\right)^{-1}=(1-16 R i)^{0.75} ;$ for $R i<0$ (unstable conditions)

The Richardson number $R i$ is estimated from potential temperature and wind speed gradient measurements $(\Delta \bar{\theta}$ and $\Delta \bar{u}$, respectively) (Kaimal and Finnigan, 1994) according to:

$R i=\frac{\frac{g}{\bar{\theta}} \frac{\Delta \bar{\theta}}{\Delta z_{\theta}}}{\left(\frac{\Delta \bar{u}}{\Delta z_{\mathrm{u}}}\right)^{2}}$

The exchange rate of a trace gas is customarily expressed as a velocity (Stull, 1988) in order to find a measure which is not dependent on the high variability of the trace gas concentration in ambient air. The ozone exchange velocity equation is related to the ozone flux (Eq. 3) by:

$v_{\mathrm{e}\left(\mathrm{O}_{3}\right)}=-\frac{F_{\mathrm{O}_{3}}}{\overline{\mathrm{O}_{3}}}$

In this study, the ozone flux (in units of $\mu \mathrm{g} \mathrm{m}^{-2} \mathrm{~s}^{-1}$ ) is expressed as exchange velocity $\left(v_{\mathrm{e}}\right)$ in $\mathrm{cm} \mathrm{s}^{-1}$. The sign convention for ozone exchange velocity is that positive 
corresponds to downward movement whereas negative corresponds to upward movement. As most of the literature have demonstrated (e.g., Oke, 1987; Stull, 1988), a time-averaging over $30 \mathrm{~min}$ is widely accepted to average over the spectrum of eddies contributing to fluxes near the surface, hence 30min averages were used in this study.

\subsection{Ozone sampling set-up}

Ambient air was drawn from each sampling height using dedicated, equal length $0.63 / 0.39 \mathrm{~cm}$ o.d./i.d. $\times 18 \mathrm{~m}$ PFA (perfluoroalkyoxy-polymer) sampling lines. An intake funnel (two-piece model 47-4 and 1-47, Savillex, Minnetonka, $\mathrm{MN}$ ) with a PTFE (polytetrafluoroethylene) membrane filter (model Mitex 5.0U, Millipore, Billerica, MA) was added to each sampling line to obstruct particles from entering the tubing. The excess tubing (for the lower tower inlet heights) was coiled and strapped to the bottom of the tower. All three sampling lines were connected to newly purchased, individual ozone UV absorption monitors (model 49C, Thermo Electron Instruments, Franklin, MA; thereafter named "TEI"). TEI ozone analyzers have previously been found to perform well in field comparisons with other UV monitors (Klaussen et al., 2003). Further information on the performance of these instruments is provided in Sect. 4.

The three analyzers were housed in a temperature controlled container $\left(\sim 20^{\circ} \mathrm{C}\right)$ in order to provide stable operating conditions and minimize instrument drifts from changes in environmental conditions across all monitors. The instrumentation was located in the "Science Trench", an underground laboratory $\sim 10 \mathrm{~m}$ directly underneath the flux tower. Before field deployment all sampling lines and inlet filters were conditioned for $24 \mathrm{~h}$ with $\sim 250 \mathrm{ppbv}$ ozone. Ozone losses during sampling through all components of the sampling system were found to be less than $2 \%$.

The TEI ozone monitors are based on a dual cell technology allowing simultaneous zero-ozone and sample measurements to be taken every $10 \mathrm{~s}$ before switching gas flows. The length and diameter of each cell are $37.8 \mathrm{~cm}$ and $1 \mathrm{~cm}$, respectively. The sampling flow rate is $\sim 1.11 \mathrm{~min}^{-1}$ and cell pressure was found to be $\sim 650 \mathrm{hPa}$ at Summit. Under these conditions the flushing time of one cell takes $\sim 1.6 \mathrm{~s}$. The standard programming of the ozone analyzer is set up to read the ozone signal during the last $3 \mathrm{~s}$ of the $10 \mathrm{~s}$ time interval. Since the cell purge flow rate could allow signal reading for up to $\sim 8 \mathrm{~s}(10 \mathrm{~s}$ minus $1.6 \mathrm{~s})$, in theory the signal acquisition time could be significantly longer than $3 \mathrm{~s}$. From counting statistics, an improvement of the measurement precision would be expected if the data acquisition time could be lengthened. To test this hypothesis, a programming change was implemented in the signal acquisition code (reprogrammed, replacement EPROM chips were provided by the instrument manufacturer) to allow the signal acquisition over the last $7 \mathrm{~s}$ of each measurement interval. The noise reduction from this longer time-integrated signal should theoretically correspond to an improvement by a factor of 1.53 (i.e., square root of 7/3). Before field deployment, all three TEI monitors were subjected to extensive analytical tests, including comparisons of results obtained with and without the modified EPROM chip. Comparison of precision tests in the laboratory and in the field before and after this modification indeed showed an improved performance of the instrument in this measurement mode, yielding on the order of slightly $<0.1 \mathrm{ppbv}$ measurement precision for data recorded as 1-min averages (see more details below). All instruments were kept at the manufactures calibration settings and corrected ozone mixing ratios were calculated from calibration functions determined from instrument calibrations performed before and after the campaign against a $\mathrm{NIST}^{1}$-referenced ozone monitor maintained by the National Oceanic and Atmospheric Administration Global Monitoring Division in Boulder, Colorado.

\subsection{Flux measurement considerations}

Several previous studies (Huntzicker and Johnson, 1979; Webb et al., 1980; Kleindienst et al., 1993; and other references mentioned below) have shown that the measurement of vertical turbulent flux of an atmospheric trace gas by micrometeorological techniques can be affected by microturbulent density fluctuations from the concomitant fluxes of heat and/or water vapor in the same volume of air. Depending on the environment and the surface type, appropriate corrections of these variations in density may be required (also known as the Webb correction) (Brook, 1978; Reinking, 1980). Consequently, both temperature and water vapor effects on the ozone flux measurements were studied prior to the deployment.

\subsubsection{Temperature effects}

Potential retention/loss of ozone in the sampling lines due to temperature changes and differences in the sampling line temperature between measurement heights was investigated by sampling an ozone standard (generated at room temperature) from a manifold with all three instruments through the $18 \mathrm{~m}$-PFA sampling tubing. When one of the sampling lines was repeatedly submerged in an ice bath while other lines remained at room temperature, there was no noticeable change in the absolute ozone measurement from that instrument as well as its precision. This test indicated that there is no change/loss of ozone in the sampling line when there is a $\sim 25^{\circ} \mathrm{C}$ difference in the tubing temperature. With the field sampling setup, by the time the sample air reaches the optical cell of the ozone UV instrument, its temperature has been equilibrated during transport through the sampling line and monitor flow path. Therefore, temperature fluctuations from vertical temperature gradients along the tower inlets

1 NIST stands for National Institute for Standards and Technology 
have been removed. Consequently the ozone gradient measurement is immune from differences in air temperature at each inlet height and there is no need to correct the ozone signal for temperature variations in the sample air.

\subsubsection{Water vapor effects}

Water vapor does not absorb at the same wavelength as ozone $(253.7 \mathrm{~nm})$, therefore, in theory, water vapor is not expected to interfere with the UV photometric ozone measurement. Nonetheless, spikes in ozone signals, either positive or negative depending on the instrument brand and environmental conditions, have been reported during situations when the sample air is subjected to rapid humidity changes. Such interferences appear to be particularly pronounced during airborne vertical boundary layer profiling when there are rapid humidity changes from flying across dry and moist air masses (Wilson and Birks, 2006). Due to the low temperatures and continental inland location, water vapor mixing ratios at Summit are much lower than under the conditions reported in these experiments. For example, at $-10^{\circ} \mathrm{C}$ the saturation water vapor pressure over ice corresponds to a mere $0.3 \%$ mole fraction of water vapor $\left(0.1 \%\right.$ at $\left.-20^{\circ} \mathrm{C}\right)$. As the monitors were operated in a temperature controlled enclosure at $\sim 30^{\circ} \mathrm{C}$, the relative humidity of the sampled air after warming up to the instrument temperature was $<5 \%$ at all times. None of the literature studies have reported measurement interferences under such dry conditions. A second concern stems from possible dilution effects, when there is a high water vapor gradient between the tower inlet heights, such as possibly during high latent heat flux or during strong temperature inversions. We do not have water vapor gradient data from Summit, but can, for a worst case assessment, use observed maximum temperature gradients $\left(5^{\circ} \mathrm{C}\right)$ at observed maximum $\left(-15 /-10^{\circ} \mathrm{C}\right)$ inlet height temperatures (when air holds the highest possible amount of water vapor) to estimate a maximum possible water vapor pressure gradient. This gradient would account to $\sim 0.7 \mathrm{hPa}$, assuming that there is water saturation at both inlet heights. This difference in water pressures would correspond to a $\sim 0.1 \%$ dilution effect. This dilution effect is $\sim 1 / 2$ of the smallest gradients that the ozone gradient measurement was able to resolve $(0.2 \%$; $0.1 \mathrm{ppbv}$ at $50 \mathrm{ppbv})$. We also considered latent heat flux data and water vapor measurements from Summit (Albert and Hawley, 2000; Cullen, 2003) to estimate water vapor changes and gradients, and the dilution effect from water vapor on the ozone mixing ratio and the ozone vertical gradient. Those assessments resulted in an estimated dilution effect even smaller than the aforementioned estimate. In conclusion, effects from atmospheric water vapor were too small to impose a considerable measurement artifact on the ozone gradient flux measurement.

\section{On-site calibrations, quality control, data corrections and filtering}

All ozone data were recorded at 1-min resolution. Instrument tests were undertaken regularly for tracking the monitor performance and for quality control. Once a week, the zero offset was determined by connecting an ozone scrubber (charcoal scrubber assembly part \#4291, TEI) to the sampling line inlet for a minimum of $15 \mathrm{~min}$. In these tests the three TEI monitors were found to have mean offsets ( \pm standard deviation, from a total of 1910 -min averaged zero test results) of $0.24 \pm 0.11,0.30 \pm 0.19$, and $0.35 \pm 0.10 \mathrm{ppbv}$, respectively. Potential drifts in the instrument sensitivity and gradient measurement offset were traced by regularly intercomparing all three monitors. For this purpose, all three inlets were placed side by side at the same height $(2 \mathrm{~m})$ and tied together so that all three monitors sampled the same ambient air composition (Fig. 1). These tests were conducted every $12 \mathrm{~h}$ for $\sim 30 \mathrm{~min}$. The record of the overall 303 half-hour inter-comparison measurements over the 136-day study period were used to identify potential drifts in the ozone monitor signal, as well as offset and measurement precision. Figure 3 shows a time series from a 30-min inter-comparison measurement, when all inlets were kept at the same height. The upper graph shows the ozone ambient air mixing ratio recorded with each monitor. The lower graph shows the 1min difference in the measurement between the three possible combinations of instrument "gradients". Since all instruments sampled the same air, the offset in the 30-min mean value (data shown in the lower graph) represents the instrument bias in the gradient measurement. The offset values from the twice daily inter-comparison experiments were traced over time as shown in Fig. 4. A two-point running mean was calculated from this series of twice-daily intercomparison data points. This running mean correction function was then used to calculate, at 1-min resolution, correction factors that were applied to the entire 1-min ozone gradient data series. The data record in Fig. 4 show that during most times, the offset between instruments was relatively stable, with changes in the relative instrument offsets between analyzers of $0.1-0.2$ ppbv between inter-comparisons. Notably, the TEI \#1 versus TEI \#3 comparison produced a more consistent data record then TEI \#1 versus TEI \#2. It is also obvious that there were several occasions when one of the analyzers experienced a 2-3 ppbv sensitivity jump. Those sensitivity changes in some cases occurred very suddenly, but in other cases happened over the course of 1-2 days. We were not able to identify any obvious causes for these sensitivity changes.

The tower gradient measurements of meteorological variables and ozone were filtered according to various instrumental and environmental criteria. Meteorological data were filtered for instruments threshold (for the cup anemometer data, a threshold value of $0.25 \mathrm{~m} \mathrm{~s}^{-1}$ was applied), wind direction, and rime buildup on the sensors. Data from the 

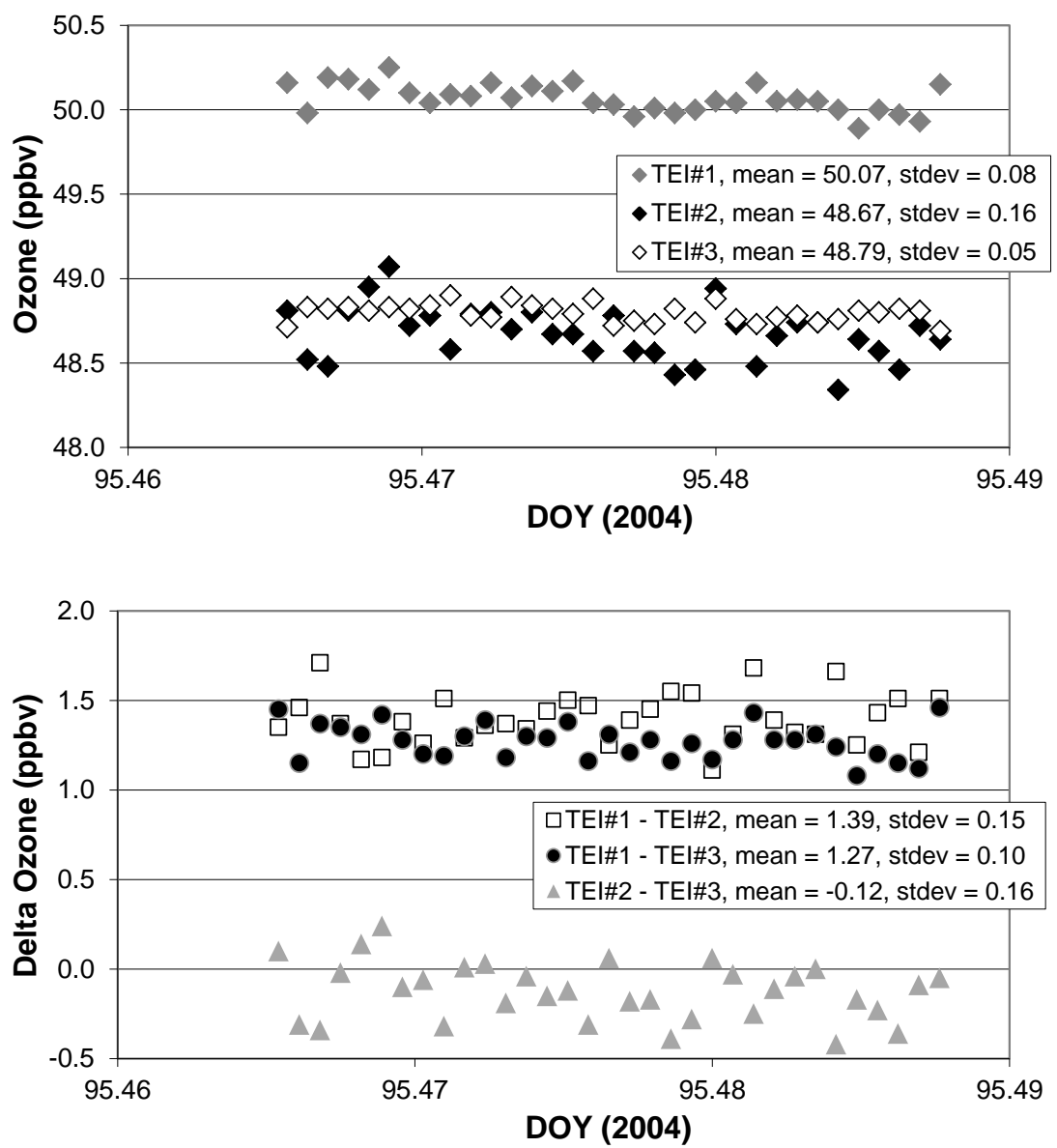

Fig. 3. Example of ozone monitor inter-comparison data set, where inlets from all three monitors were kept at the same height for determination of the instrument offset and precision of the gradient measurement. The upper graph shows the actual measurement from each monitor. The bottom graph shows the calculated "gradient" during the same period.

$320^{\circ}$ to $35^{\circ} \mathrm{N}$ sector were eliminated due to tower shadowing and air flow from the camp. Ozone data were examined for miscellaneous artifacts such as low sampling flow rate readings (only observed once in one of the ozone monitors) and low monitor temperature when the instrument container was opened for instrument maintenance. Data processing also included filtering for atmospheric stability $(-0.1<R i<0.1)$, boundary layer height (PBL had to be greater than $100 \mathrm{~m}$ for $\{10-2 \mathrm{~m}\}$ fluxes and greater than $20 \mathrm{~m}$ for $\{2-0.75 \mathrm{~m}\}$ fluxes), and friction velocity $\left(0.05<u^{*}<0.5 \mathrm{~m} \mathrm{~s}^{-1}\right)$, where $u^{*}$ was calculated according to

$u^{*}=k \frac{\Delta u}{\left(\ln \frac{z_{2}}{z_{1}}\right)}\left(\Phi_{\mathrm{M}}\right)^{-1}$

where $k$ is again the Von Karman constant. As mentioned above, the gradient flux measurement method holds for nearneutral atmospheric conditions. The applicability of the stability correction functions was examined by comparing heat and momentum flux results derived from sonic anemometer turbulence measurements (mounted at $\sim 2 \mathrm{~m}$ on the tower from June to the end of the study period) with calculations of these same variables from the gradient measurements. For this purpose, the atmospheric stability parameter $z / L$, where $z$ is the distance from the ground and $L$ is the Monin-Obukhov length, was calculated from the turbulence measurements, and converted to the Richardson number ( $R$, derived from the gradient measurements) according to the relationships given by Kaimal and Finnigan (1994). The comparison showed that the best agreement (correlation with $R^{2} \sim 0.65$ ) was obtained for $R i$ numbers of $-0.10<R i<+0.10$. Approximately $95 \%$ of the flux data fell within this range. Data outside of this range of $R i$ values were discarded as it appeared that the gradient method would overestimate fluxes owing to an overestimation of the stability function correction (Cohen, 2006; Cohen et al., 2007).

Another requirement for the flux gradient method is that measurements have to be conducted within the atmospheric surface layer (also known as the constant flux layer), which is defined as the lowest $10 \%$ of the mixed boundary layer. Since direct mixed boundary layer height measurements 


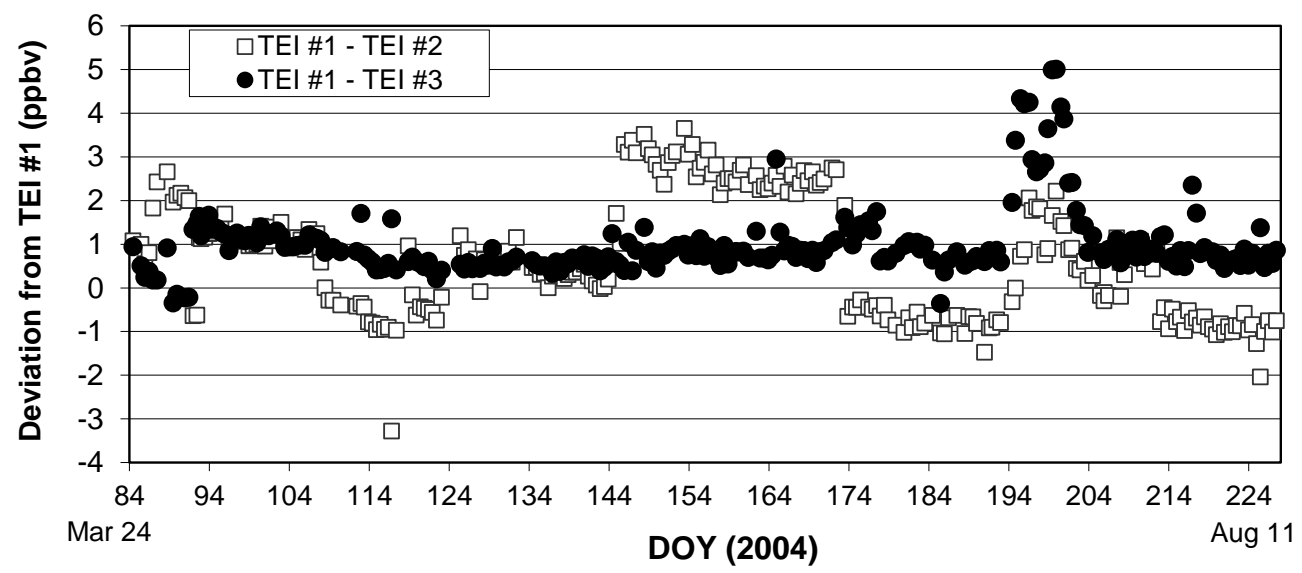

Fig. 4. Record of results in the TEI instrument deviations from the twice-daily inter-comparison measurements.

were not available, the boundary layer height $H$ was estimated using the equation given by Pollard et al. (1973):

$H=1.2 u \cdot(f N)^{-0.5}$

where $f$ is the Coriolis force $\left(\mathrm{s}^{-1}\right)$ and $N$ is the BrüntVäisälä frequency $\left(\mathrm{s}^{-1}\right)$. Neff et al. (2007) reported that this simple equation gave good results compared to other techniques, such as minisodar and tethered balloon for measurements over snow. Cohen et al. (2007) recently used the equation to calculate boundary layer heights at Summit and reported that boundary layer heights are lowest during the night and reached their peaks during daytime, with heights of 250 $400 \mathrm{~m}$. A filter was then applied eliminating data when $H$ was below $100 \mathrm{~m}$ and $20 \mathrm{~m}$ for the $\{10-2 \mathrm{~m}\}$ and $\{2-0.75 \mathrm{~m}\}$ gradient measurements, respectively.

Another filter was applied to remove flux data for periods when winds were low, as under those conditions either cup anemometers did not work properly or atmospheric turbulence was not fully developed for flux calculations. We also eliminated data from very high wind conditions, where gradients became too small to be identified by our measurements. This filter was based on calculations of the friction velocity, $u^{*}$. Data were excluded when friction velocity was lower than a critical value of $0.05 \mathrm{~m} \mathrm{~s}^{-1}$ or higher than $0.5 \mathrm{~m} \mathrm{~s}^{-1}$.

Applying all the above mentioned filters removed a total of $\sim 57 \%$ of data from the entire (6500) 30-min flux gradient data averages (Bocquet, 2007). Table 1 provides the details of how much data were removed by each of the filter criteria for the spring (here defined as day of year (DOY) 92-152) and summer period (DOY 153-227). This data rejection created data gaps of various lengths ranging from 1 point, i.e., $30 \mathrm{~min}$, to about 30 data points, i.e., $\sim$ half a day). These gaps can potentially bias analyses from subsequent calculations and interpretations of fluxes (e.g., Goulden et al., 1996; Oren et al., 2006; Dragoni et al., 2007). As gap filling increases uncertainty of calculated fluxes (Falge et al., 2001a, b) we did not pursue this approach.

\section{Monte Carlo simulations}

The relative contribution of individual input variables to the uncertainty of the flux determination was assessed by Monte Carlo simulation. The uncertainty was calculated for the 30-min average ozone exchange measurement results obtained for both the $\{2-0.75 \mathrm{~m}\}$ and $\{10-2 \mathrm{~m}\}$ gradient measurements. Thirty-min averages and estimated uncertainties were used for each pair of the air temperature gradient, wind speed gradient, ozone mixing ratio gradient, measurement height gradient, and ambient pressure. For temperature, wind speed and ozone mixing ratio, measurement uncertainty estimates were derived from the ensemble of inter-comparison experiments while for ambient pressure and heights, uncertainty estimates were derived from estimates of sensor accuracy and measurement precision, respectively. Utilized uncertainty values (see further discussion below) were $0.05^{\circ} \mathrm{C}$ for the temperature measurement, $0.05 \mathrm{~m} \mathrm{~s}^{-1}$ for the wind speed measurement, $0.1 \mathrm{ppbv}$ for the ozone determination, $0.5 \mathrm{hPa}$ for the pressure measurement, and $5 \mathrm{~cm}$ for the measurement height. Furthermore, the ranges of the input variables that were tested by Monte Carlo simulations were -40 to $-10^{\circ} \mathrm{C}$ for temperature, 1 to $10 \mathrm{~m} \mathrm{~s}^{-1}$ for wind speed, and 35 to 65 ppbv for ozone. A total of 5000 Monte Carlo simulations were run for each calculated 30-min ozone exchange velocity, providing an uncertainty value for each 30-min ozone exchange velocity. The Monte Carlo sensitivity analysis also investigated how the distribution of the output variable $\left(v_{\mathrm{e}}\left(\mathrm{O}_{3}\right)\right)$ varied with changes in only one input variable (while all other input variables are held constant at their 30min value). This analysis, called the nominal-range analysis, was used to determine which input variable(s) had the largest influence on the output uncertainty. 
Table 1. Percentage of data that were removed by ten successive quality control filters. Each row lists the additional percentage of data that were eliminated from the data remaining after applying all preceding filters. Spring=DOY 92-152 (1 April-31 May); Summer=DOY 153-227 (1 June-14 August).

\begin{tabular}{|c|c|c|c|c|}
\hline & Data rejected based on & $\begin{array}{r}\text { Total } \\
\% \text { value }\end{array}$ & $\begin{array}{r}\text { Spring } \\
\text { (DOY 92-152) }\end{array}$ & $\begin{array}{r}\text { Summer } \\
\text { (DOY 153-227) }\end{array}$ \\
\hline 1 & Daily inter-comparisons/Calibrations (zero $\mathrm{O}_{3}$ tests in begin $/ \mathrm{mid} / \mathrm{end}$ seasons) & 6.6 & 5.7 & 7.2 \\
\hline 2 & Bad wind direction (from camp and through tower) & 5.5 & 4.2 & 6.6 \\
\hline 3 & Instruments thresholds (e.g., WS) & 2.2 & 3.4 & 1.3 \\
\hline 4 & Environmental artifacts (e.g., rime) & 0.8 & 0.8 & 0.8 \\
\hline 5 & Missing data (either $\mathrm{O}_{3}$, WS or T sensors) & 9.5 & 19.7 & 1.7 \\
\hline 6 & Miscelleneous (instrument maintenance, etc.) & 15.9 & 3.4 & 25.6 \\
\hline 7 & Atmospheric stability $(R i)$ outside of $-0.1<R i\{2-0.75 \mathrm{~m}\}<+0.1$ & 12.2 & 12.6 & 11.8 \\
\hline 8 & Sensible heat flux $(Q h)$ outside of $-40<Q(h)<+70 \mathrm{~W} \mathrm{~m}^{-2}$ & 0.2 & 0.1 & 0.2 \\
\hline \multirow[t]{3}{*}{9} & Boundary layer height (PBL) & & & \\
\hline & $\mathrm{PBL}<100 \mathrm{~m}$ for $\{10-2 \mathrm{~m}\}$ & 2.6 & 1.0 & 3.4 \\
\hline & $\mathrm{PBL}<20 \mathrm{~m}$ for $\{2-0.75 \mathrm{~m}\}$ & 0.0 & 0.0 & 0.0 \\
\hline \multirow[t]{5}{*}{10} & Friction velocity $\left(u^{*}\right)$ outside of $0.05<u^{*}<0.5 \mathrm{~m} \mathrm{~s}^{-1}$ & 0.2 & 0.2 & 0.2 \\
\hline & Total data filtered out for: & & & \\
\hline & $\{2-0.75 \mathrm{~m}\}$ layer & 57.3 & 64.7 & $49.9 \%$ \\
\hline & $\{10-2 \mathrm{~m}\}$ layer & 78.1 & 82.4 & $73.7 \%$ \\
\hline & $\{10-0.75 \mathrm{~m}\}$ layer & 75.6 & 81.6 & $69.6 \%$ \\
\hline
\end{tabular}

\section{Results and discussion}

\subsection{Characterization of measurement precision/accuracy}

Sensors for wind speed and temperature gradients were intercompared at the beginning, mid-term, and at the end of the campaign by moving the instruments to the same height for 1-2 days. The insert in Fig. 1 depicts the arrangement for the wind speed sensor inter-comparison. The data obtained from these periods were carefully evaluated and polynomialfit correction functions were determined by which two of the sensors were corrected to the third one. Figure 5 presents an example of the raw inter-comparison data for the wind speed and the temperature gradient measurements. The wind speed measurements showed a high level of agreement. Deviations in the uncorrected data between the three wind speed sensors were generally $<0.2 \mathrm{~m} \mathrm{~s}^{-1}$. After applying the correction functions the deviation between the three sensors was $<0.05 \mathrm{~m} \mathrm{~s}^{-1}$. Similar results have been obtained for these instruments in two other subsequent field campaigns. Deviations in the temperature measurements were more variable, depending on the particular sensor pair and time of day. A particular difficulty stemmed from variable response of the three sensors during high solar irradiance conditions. This effect was identified during the temperature inter-calibration experiments, and most pronounced during sunny, mid-day summer conditions. From the data example in Fig. 5, it is obvious that while there was good agreement during the nighttime and morning hours, the temperature measurement from the $10 \mathrm{~m}$-instrument was biased by up to $0.5-0.6^{\circ} \mathrm{C}$ during times of maximum solar irradiance. Furthermore, it is obvious that the measurement from the $10-\mathrm{m}$ instrument was noisier than for the two other sensors. This effect has been related to the high albedo of the snow surface, exposing the downwards pointing aspirator inlets to variable and at times high levels of upward dwelling irradiance depending on time of day and solar zenith angle. Further discussion and approaches for correction are discussed by Cohen (2006). The study by Cohen also presented a comparison between results for the heat flux calculations from the tower gradient measurements with directly measured eddy covariance heat flux results. While both data sets agreed well during night and twilight hours, gradient heat flux results during noon hours were up to three times larger than eddy covariance results. These findings motivated Cohen to determine ozone surface fluxes by the "modified gradient" technique, where fluxes were determined using the ozone gradient, and the sonic anemometer turbulence measurements.

The temperature sensor inter-comparisons showed that overall disagreement in the uncorrected temperature gradient data was up to $0.6^{\circ} \mathrm{C}$, with the lower gradient pair typically yielding a lower error than for the tower upper gradient temperature. Data from the inter-comparison periods were subjected to a correction algorithm that had a dependency on solar irradiance. This same algorithm was then also applied to the subsequent inter-comparison (conducted 1-2 months 

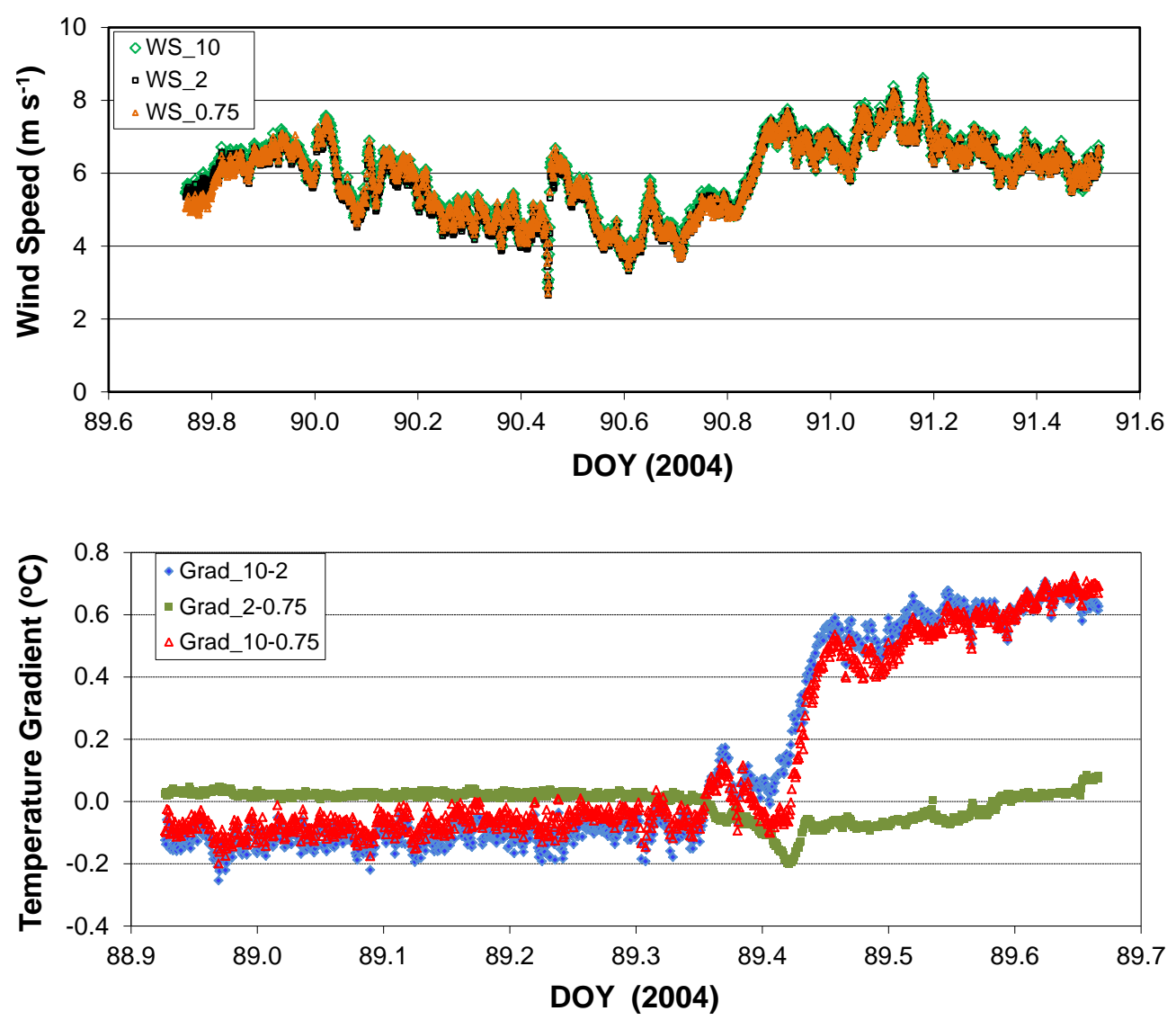

Fig. 5. Example of results from the inter-comparison measurement during DOY 89-91 (29-31 March) (upper graph) and DOY 89 (29 March) (lower graph), where the three instruments were brought to the same height and run side by side. The upper graph shows $\sim 1$ day of wind speed data from the three cup anemometers prior to being subjected to correction functions. WS_10, WS_2, and WS_0.75 refer to the instruments that were operated at the $10 \mathrm{~m}, 2 \mathrm{~m}$ and $0.75 \mathrm{~m}$ height, respectively. Deviations in data between the sensors were on average less than $2 \%$, almost indiscernible in this plot. The bottom graph shows the raw, uncorrected data from the inter-comparison of the temperature sensors. Gradients were determined directly. For example, "Grad 10-2" stands for the gradient measurement between the 10- and the 2- $\mathrm{m}$ measurement height. Deviations from zero are due to instrument noise and measurement artifact (see discussion in Sect. 6.1).

later), and residual errors between these measurements were then estimated from the deviation of the data during this experiment. For the Summit 2004 experiment, we estimate the accuracy of the temperature gradient measurement, after applying the correction functions, to be $0.05-0.1^{\circ} \mathrm{C}$ for the lower gradient interval, and $0.2{ }^{\circ} \mathrm{C}$ for gradients that include measurements from the $10-\mathrm{m}$ tower height. In a subsequent experiment at Summit, using new thermocouple wires with the same instruments, and a slightly different intercomparison procedure, similar effects were observed during high solar irradiance conditions. For that experiment the residual accuracy error of the temperature gradient determination was estimated to be $0.10-0.15^{\circ} \mathrm{C}$. Please note that a $50 \%$ reduced variability during high irradiance conditions has since been achieved with a different aspirated temperature instrument (model 41342 sensor and model 43502 aspirated shield, RM Young Company, Traverse City, MI), using a platinum RTD sensor instead of thermocouple wires.
In summary, for the 2004 experimental conditions, the estimated residual accuracy errors in the wind speed and temperature gradient determinations were on the order of $0.05 \mathrm{~m} \mathrm{~s}^{-1}$ and $0.1^{\circ} \mathrm{C}$. Since fluxes were calculated from thirty 1-min data points, the precision error is reduced by a factor of $1 / \sqrt{30}$. Consequently, the precision error of the wind speed and temperature measurement is relatively small in relation to the accuracy error, resulting in the overall uncertainty in the 30-min data to be primarily determined by the accuracy of the measurement. Therefore, the uncertainty estimate was based on the estimation of the accuracy error of this determination.

Precision and accuracy of the ozone measurements were estimated from the twice-daily inter-comparisons. Over the 30-min inter-comparisons period, the standard deviation calculated for the 1-min data reflects both the precision of the measurement $(\sigma)$ and the change of ambient ozone in time 

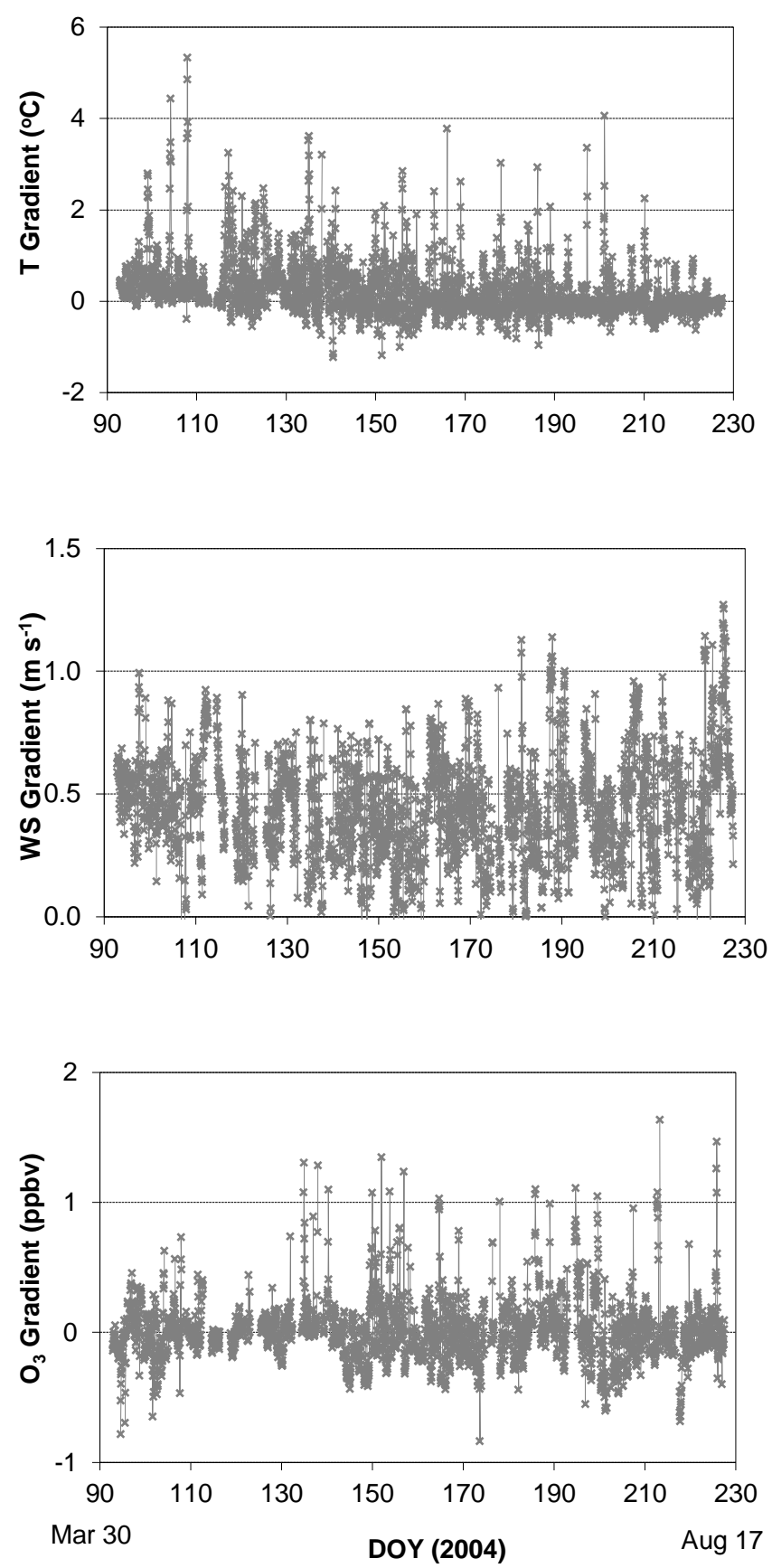

Fig. 6. The $\{2-0.75 \mathrm{~m}\}$ gradients for temperature $(T)$, wind speed (WS) and ozone $\left(\mathrm{O}_{3}\right)$ during the 2004 experiment.

$\left(\Delta \mathrm{O}_{3, \mathrm{amb}} / \Delta t\right)$ :

$\frac{\mathrm{dO}_{3}}{\mathrm{~d} t}=\sigma+\frac{\Delta \mathrm{O}_{3, \mathrm{amb}}}{\Delta t}$

When the change of ambient ozone in time $\left(\Delta \mathrm{O}_{3, \mathrm{amb}} / \Delta t\right)$ over 30-min becomes small (i.e., during conditions when ambient air ozone concentrations do not change), this measurement allows to estimate an approximate value of the precision of the ambient ozone measurement of each monitor.
Secondly, the inter-comparison measurements allow determining the offset for the ozone gradient measurement, as well as the accuracy and precision of the gradient determination. The inter-comparison example shown in Fig. 3 reflects a case with relatively stable ozone concentrations. The deviations between the 1-min ozone readings mostly reflect the precision of the ozone measurement for each analyzer. For this particular example, the variability/precision over the 30min measurement period was $0.08,0.16$, and $0.05 \mathrm{ppbv}$ for monitors TEI \#1, 2, and 3, respectively. Obviously, there is a factor of approximately 3 difference in the achieved precision between these three monitors. As all three instruments had the exact same configuration and history, there was no obvious reason for this difference in performance. A histogram of the results from all $\sim 300$ inter-comparisons showed that the TEI monitors under these deployment conditions yielded a best case 1-min measurement precision on the order of $0.05-$ $0.08 \mathrm{ppbv}$ during the 30 -min periods. From that, using error propagation rules, one would theoretically expect a precision of the gradient measurement of $0.07-0.11 \mathrm{ppbv}$. This estimate agrees well with the calculation of the "gradient" measurements during the inter-comparison periods. The average precision for the three ozone differentials from all experiments was $0.098 / 0.085 / 0.11 \mathrm{ppbv}$ for the three instrument pairs. Since precision errors are additive in the ozone gradient determination, the error for the 30 -min mean values, derived from the 1-min gradients data are estimated to account to (divided by $\sqrt{30}$ ) $0.02-0.03$ ppbv. Consequently, similarly as for the wind speed and temperature measurement, the uncertainty in the ozone measurement is primarily due to the accuracy of the ozone measurement, which in turn, is mostly determined by the sensitivity drift of each individual analyzer over time. From the extensive testing and inter-comparisons of the three TEI, we estimated the overall uncertainty in the corrected ozone gradient determination to be $\sim 0.1 \mathrm{ppbv}$.

\subsection{Gradient data}

The gradient results for temperature, wind speed, and ozone for the entire campaign for the $\{2-0.75 \mathrm{~m}\}$ gradient height are shown in Fig. 6. These data reflect the tower gradients that were determined after application of all corrections and filters as discussed above. Most temperature gradients were in the $0-1{ }^{\circ} \mathrm{C}$ range, with occasional values approaching $3-5^{\circ} \mathrm{C}$. Those higher values resulted from stable stratification during nighttime conditions, when strong inversion layers over the cold snow surface were encountered. These conditions typically fell outside of the stability range considered for flux calculations. Negative gradients, on the order of 0 to $-1{ }^{\circ} \mathrm{C}$, occurred during daytime, when the snow surface was heated by solar irradiance, causing convective heat transport. There is a tendency of less positive and more negative gradients, respresenting more unstable conditions, towards the mid-summer. Wind speeds at the 2$\mathrm{m}$ height were always higher than at $0.75 \mathrm{~m}$, causing wind 

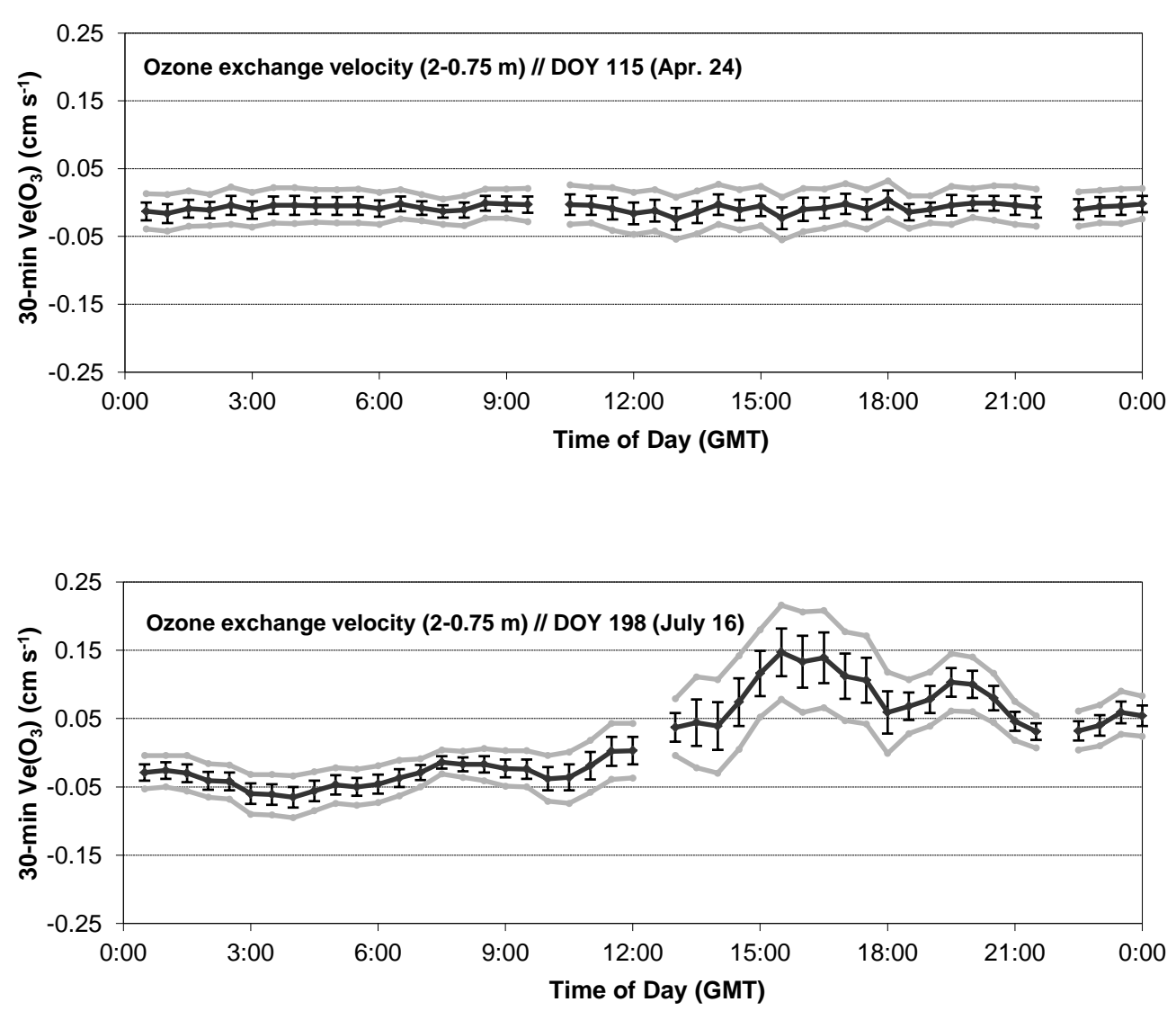

Fig. 7. Results for the ozone deposition velocity determination for layer $\{2-0.75 \mathrm{~m}\}$ for two examples from a day during the spring (DOY 115 [24 April]) and the summer (DOY 198 [16 July]) 2004 periods. Error bars represent the 1- $\sigma$ uncertainty from 5000 Monte Carlo simulations, while grey lines represent the lower and upper $95 \%$ confidence levels $(2 \sigma)$ for each 30-min gradient flux calculation. Gaps in the time series are due to the inter-comparison periods. Summit local time is $2 \mathrm{~h}$ earlier than GMT.

speed gradients to always be positive. There was a large variability in wind speed gradients, ranging from $<0.1$ to $\sim 1.2 \mathrm{~m} \mathrm{~s}^{-1}$. Ozone gradients between the lower two tower inlets exceeded $\pm 1 \mathrm{ppbv}$ on occasions, but most gradients were in the order of tenths of ppbv or smaller.

\subsection{Uncertainty in the ozone flux determined by Monte Carlo calculations}

An uncertainty estimate in the ozone flux (deposition velocity) determination was derived from the Monte Carlo simulation for each 30-min flux average interval. Figure 7 shows two examples of 30-min deposition velocity results for a spring and summer day, with the 1- $\sigma$ and 2- $\sigma$ uncertainty estimate margins added to the data. These simulations yielded an estimated uncertainty $(1 \sigma)$ in the ozone exchange velocity result from 0.005 to $0.038 \mathrm{~cm} \mathrm{~s}^{-1}$ ) in this particular example. The review of all simulations yielded a median uncertainty on the order of $10^{-2} \mathrm{~cm} \mathrm{~s}^{-1}$. It is obvious that the uncertainty in the data has a significant magnitude in relation to the overall size of the signal (high relative error). Another

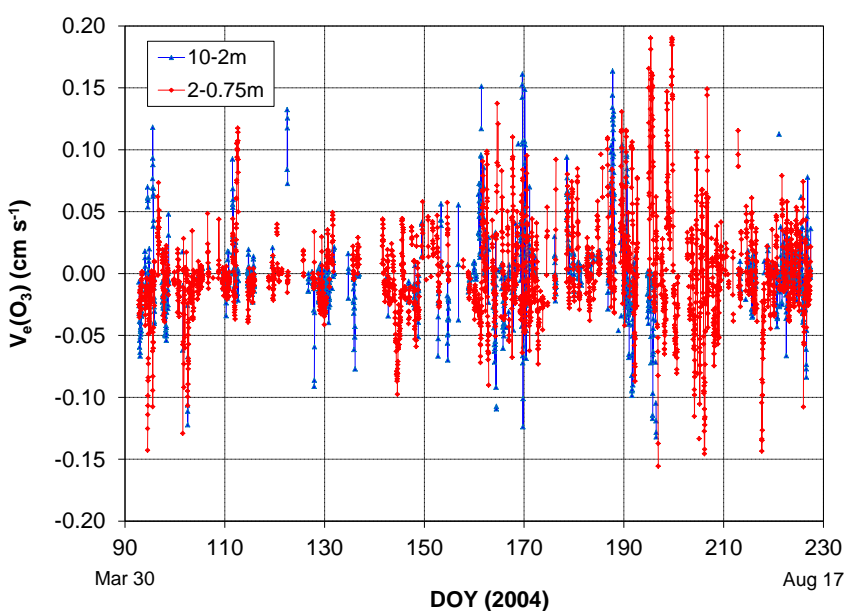

Fig. 8. Ozone exchange velocity results from the $\{10-2 \mathrm{~m}\}$ and $\{2-0.75 \mathrm{~m}\}$ gradients for the entire experiment. 
notable observation is that the absolute value of the uncertainty increases with the size of the signal. Besides providing the uncertainty estimate of each individual flux result, this calculation also allowed evaluating the relative contribution of the measured variables towards the overall ozone flux uncertainty. The review of these results showed that there is a high variability in the relative contribution of individual measurements to the uncertainty in the flux result. This stems from the fact that gradient results, depending on encountered conditions, are highly variable. Typically, gradients for temperature and ozone increase with increasing atmospheric stability, conditions that at Summit are more prominent earlier in the year, and during nighttime. When gradients are large, the relative uncertainty in the gradient measurement (and flux determination) becomes smaller. Vice versa, moving towards neutral and unstable conditions, as gradients become smaller, the relative uncertainty in the measurement increases, causing a larger uncertainty in the ozone flux determination. This explains the earlier noted observation, i.e., that the absolute value in the uncertainty in the flux result is highest during times when fluxes are highest. A review of the 300+ Monte Carlo outputs showed that the ozone measurement typically had the highest contribution to the overall variability in the outputs, contributing on the order of 50$90 \%$ to the variance. The second highest contribution was from the wind speed measurement, followed by the temperature measurement, the height determination, and pressure. The relatively low ranking and contribution of the temperature variable was somewhat surprising. Particularly during unstable conditions, temperature gradients in the surface layer become small, turning the measurement uncertainty in the gradient measurement into a relative large error. There is an obvious explanation for the robustness of the flux determination towards the uncertainty in the temperature measurement. In the flux calculation, the temperature gradient is factored in through the computation of $R i$ and the stability function. Those correction factors become increasingly important with increasing departure from neutral stability conditions. Since data were previously rigorously filtered for atmospheric stability, the remaining data set reflects mostly near-neutral conditions, where stability functions calculated with the temperature data have a lower influence on the flux calculation.

\subsection{Ozone deposition results}

Ozone $v_{\mathrm{e}}$ results from the entire 2004 campaign are shown in Fig. 8. Gaps in the data plot are, as discussed above, mostly due to exclusion of measurement periods from the data filtering. Determined ozone $v_{\mathrm{e}}$ values show a significant variability, but generally fall within the range of -0.05 to $+0.15 \mathrm{~cm} \mathrm{~s}^{-1}$. There is a tendency towards larger ozone deposition fluxes, and more distinct diurnal cycles towards the summer months. This behavior is most apparent in the averaged ( 1 week) diurnal cycles shown for one spring and one late summer week in Fig. 9. During spring, ozone $v_{\mathrm{e}}$ fall within the narrow range of $0.00 \pm-0.01 \mathrm{~cm} \mathrm{~s}^{-1}$. During summertime, nighttime minima and afternoon maxima are up to 10-15 times larger. Results from these flux gradient determinations are in good agreement with calculations by Helmig et al. (2009b), who used sonic anemometer data and ozone concentration gradients for calculating ozone fluxes from this same summer data set, as well as from a later springtime experiment(spring 2005). The dependency of the ozone flux on wind speed and solar irradiance, both during spring and during summer, is shown in Fig. 10. During summer, there is an obvious tendency of larger ozone deposition fluxes at times of high solar irradiance, and during high winds. This behavior can be explained by apparent ozone destruction seen inside the snowpack and wind pumping effects, causing faster exchange of snowpack interstitial air with the atmosphere above the snow during high winds. The data shown in Fig. 9 and Helmig et al. (2009b) illustrate that during certain times there appears to be an upward flux of ozone from the snow surface. This behavior suggests ozone production near the snow surface. Elucidation of the underlying chemical processes driving this phenomenon is the context of new research that builds upon the findings from the studies presented here.

\subsection{Evaluation of the ozone flux method}

The measurement uncertainty of approximately $0.01 \mathrm{~cm} \mathrm{~s}^{-1}$ for the ozone exchange velocity allowed deciphering the general seasonal behavior of the ozone flux behavior at Summit, as well as diurnal changes during the summer. However, the achieved sensitivity was not sufficient for resolving fine scale flux behavior during the winter period. There are few other studies that have accomplished ozone flux measurements at this sensitivity, respectively that have provided characterization of their achieved flux measurement sensitivity. We are not aware of any research that has reported higher sensitivity (respectively lower uncertainty) in ozone flux determination. Recently, Bariteau et al. (2010) described an eddy covariance method for ozone flux measurements from a ship-borne platform for the study of ozone uptake to the ocean. Similarly to snow, ozone uptake rates to water were found to be low, with deposition velocities on the order of $0.01-0.05 \mathrm{~cm} \mathrm{~s}^{-1}$. This eddy covariance system achieved a similar resolution as our gradient method reported here, enabling a measurement resolution of approximately $0.01 \mathrm{~cm} \mathrm{~s}^{-1}$.

\section{$7 \quad$ Summary and conclusions}

These experiments define a protocol for ozone flux measurements by the gradient method using off-the-shelf meteorological and chemical sensors. Inter-comparison measurements that were conducted by bringing meteorological and chemical sensors (inlet height) to the same height were found 

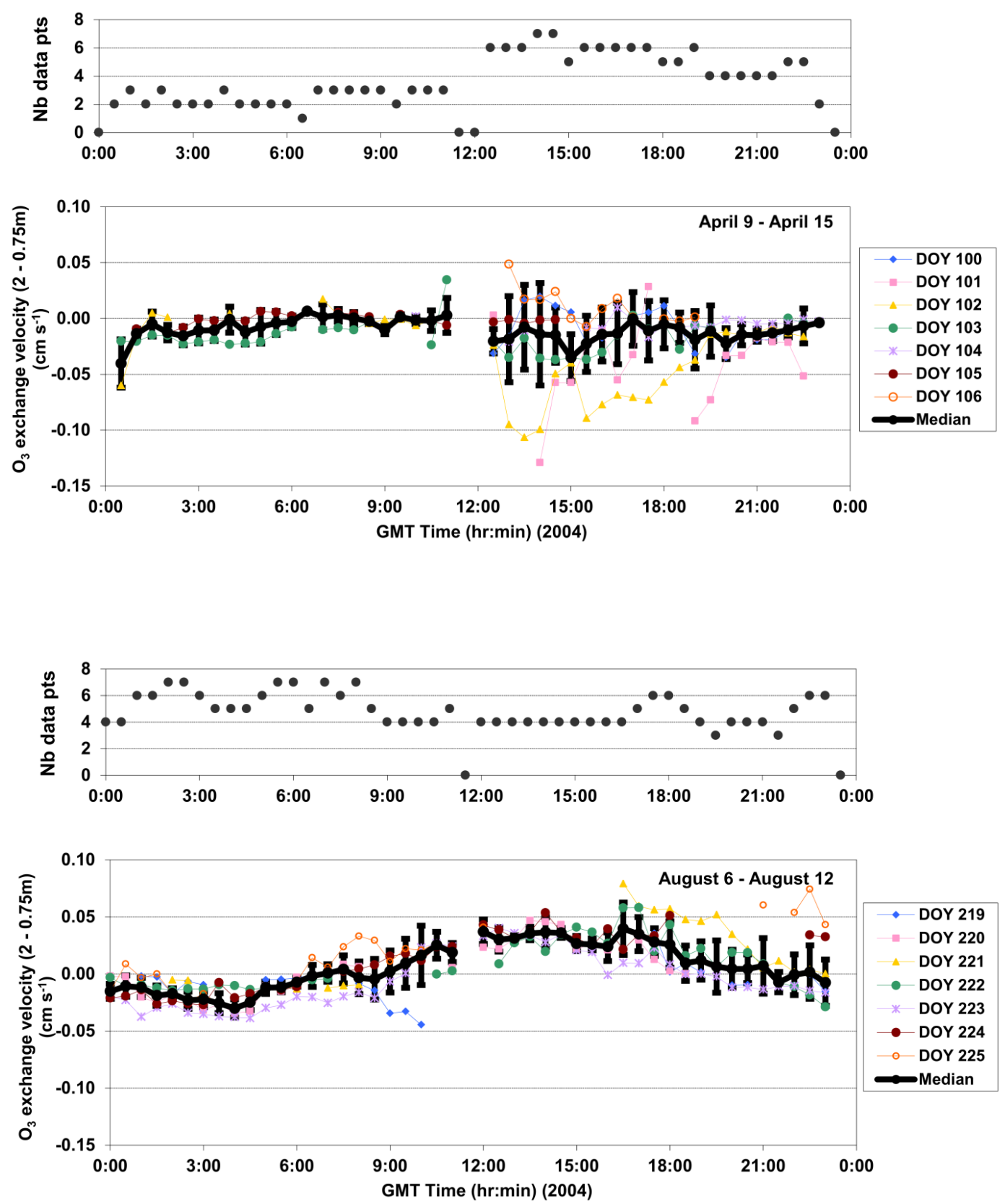

Fig. 9. Mean diurnal cycle of ozone $v_{e}$ for one week in spring (top; DOY 100-106 [9-25 April]) and summer (bottom; DOY 219-225 [612 August]). Both graphs also show the number of individual data points (days) that went into the mean and standard deviation (as indicated by the error bar) calculation.

to be an essential step for minimizing the uncertainty in the gradient determination and flux calculation. This finding is in agreement to the previous study reported by Dragoni et al. (2007). Using our protocol, the uncertainty in the ozone measurement was reduced to $\sim 0.1 \mathrm{ppbv}$ for 30 -min averaged ozone gradient data. These measurements allowed deciphering ozone exchange velocities on the order of $\sim 10^{-2} \mathrm{~cm} \mathrm{~s}^{-1}$ in magnitude. This is one of the most sensitive ozone flux determinations reported in the literature to date. Monte Carlo simulations showed an uncertainty of the 30-min ozone exchange velocity on the order of magnitude of $10^{-2} \mathrm{~cm} \mathrm{~s}^{-1}$. The Monte Carlo sensitivity analysis revealed that the gradient measurements of the ozone mixing ratio is the variable having the highest contribution towards the uncertainty in the ozone flux measurement, followed by the wind speed gradient and temperature gradient measurement. 

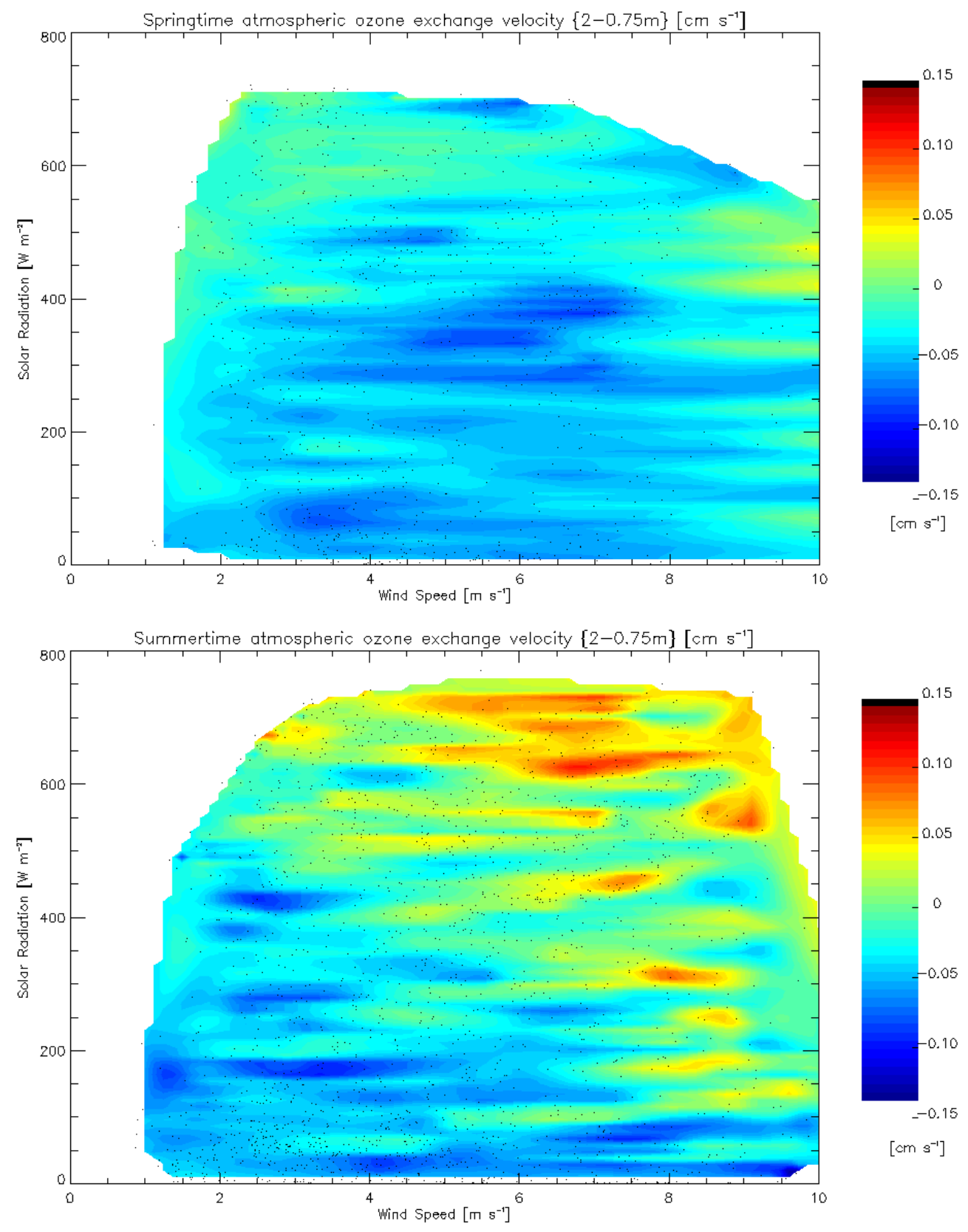

Fig. 10. Color contour display of the ozone exchange velocity as a function of wind speed and solar irradiance for the spring (top) and summer (bottom) periods. Black dots indicate the distribution of individual data points that were included in the contour plot analyses.

Measurements conducted at Summit resulted in ozone exchange velocity $v_{\mathrm{e}}$ values on the order of $0.01 \pm-0.01 \mathrm{~cm} \mathrm{~s}^{-1}$ during spring, and between -0.03 to $0.15 \mathrm{~cm} \mathrm{~s}^{-1}$ during summer. During summer, ozone fluxes showed a distinct diurnal cycle, with increased ozone deposition rates occurring during mid-afternoon hours. Results also showed increase of ozone $v_{\mathrm{e}}$ with increasing winds, an effect that can be explained by faster exchange of ozone depleted air in the snowpack from wind pumping. These findings provide new constraints for the numerical representation of ozone deposition to snow in polar regions. As our ozone $v_{\mathrm{e}}$ from Summit in general are smaller than the previously reported data from mid-latitudes, and smaller than ozone $v_{\mathrm{e}}$ currently considered in most atmospheric chemical and transport models, incorporation of these new findings will result in longer simulated ozone lifetimes, and higher surface layer ozone levels in the polar regions. 


\section{Supplementary material related to this article is available online at: \\ http://www.atmos-meas-tech.net/4/2305/2011/ amt-4-2305-2011-supplement.pdf.}

Acknowledgements. This research was supported through the United States National Science Foundation (Office of Polar Programs OPP \#240976). We thank Thermo Fisher Scientific for modifying the TEI 49C ozone monitor data acquisition program. Logistical support was provided by VECO Polar Resources and the US $109^{\text {th }}$ Air National Guard. We also thank the Danish Commission for Scientific Research for providing access to the Summit research site.

Edited by: J. Stutz

\section{References}

Albert, M. R. and Hawley, R. L.: Seasonal differences in surface energy exchange and accumulation at Summit, Greenland. Ann. Glac., 31, 387-390, 2000.

Aldaz, L.: Flux measurements of atmospheric ozone over land and water, J. Geophys. Res., 74, 6934-6946, 1969.

Bariteau, L., Helmig, D., Fairall, C. W., Hare, J. E., Hueber, J., and Lang, E. K.: Determination of oceanic ozone deposition by shipborne eddy covariance flux measurements, Atmos. Meas. Tech., 3, 441-455, doi:10.5194/amt-3-441-2010, 2010.

Bocquet, F.: Surface layer ozone dynamics and air-snow interactions at Summit, Greenland: spring and summer ozone exchange velocity and snowpack ozone-the complex interactions, Unpublished $\mathrm{PhD}$ thesis, University of Colorado, Boulder, 247 pp., 2007.

Brook, R. R.: The influence of water vapor fluctuations on turbulent fluxes, Bound.-Lay Meteorol., 15, 481-487, 1978.

Cohen, L.: Boundary layer characteristics and ozone fluxes at Summit, Greenland, M.S. Thesis, University of Colorado, 2006.

Cohen, L., Helmig, D., Neff, W., Grachev, A., and Fairall, C.: Boundary-layer dynamics and its influence on atmospheric chemistry at Summit, Greenland, Atmos. Environ., 41, 50445060, 2007.

Colbeck, I. and Harrison, R. H.: Dry deposition of ozone: some measurements of deposition velocity and of vertical profiles to 100 meters, Atmos. Environ., 19, 1807-1818, 1985.

Cullen, N. J.: Characteristics of the atmospheric boundary layer at Summit, Greenland, Unpublished $\mathrm{PhD}$ thesis, University of Colorado at Boulder, 2003.

Dabberdt, W. F., Lenschow, D. H., Horst, T. W., Zimmerman, P. R., Oncley, S. P., and Delany, A. C.: Atmosphere-surface exchange measurements, Science, 260, 1472-1481, 1993.

Dragoni, D., Schmid, H. P., Grimmond, C. S. B., and Loescher, H. W.: Uncertainty of annual net ecosystem productivity estimated using eddy covariance flux measurements, J. Geophys. Res., 112, D17102, doi:10.1029/2006JD008149, 2007.

Falge, E., Baldocchi, D., Olson, R.J., Anthoni, P., Aubinet, M., Bernhofer, C., Burba, G., Ceulemans, R., Clement, R., Dolman, H., Granier, A., Gross, P., Grunwald, T., Hollinger D., Jensen N.-O., Katul, G., Keronen P., Kowalski, A., Chun, T.L., Law, B., Meyers, T., Moncrieff, J., Moors, E., Munger, W., Pilegaard, K.,
Rannik, Ü., Rebmann, C., Suyker, A., Tenhunen, J., Tu, K., Verma, S., Vesala, T., Wilson, K., and Wofsy, S.: Gap filling strategies for defensible annual sums of net ecosystem exchange, Agric. Forest Meteorol., 107, 43-69, 2001a.

Falge, E., Baldocchi, D., Olson, R.J., Anthoni, P., Aubinet, M., Bernhofer, C., Burba, G., Ceulemans, R., Clement, R., Dolman, H., Granier, A., Gross, P., Grunwald, T., Hollinger D., Jensen N.-O., Katul, G., Keronen P., Kowalski, A., Chun, T.L., Law, B., Meyers, T., Moncrieff, J., Moors, E., Munger, W., Pilegaard, K., Rannik, Ü., Rebmann, C., Suyker, A., Tenhunen, J., Tu, K., Verma, S., Vesala, T., Wilson, K., and Wofsy, S.: Gap filling strategies for long-term energy flux data sets, a short communication, Agric. Forest Meteorol., 107, 71-177, $2001 \mathrm{~b}$.

Galbally, I.: Some measurements of ozone variation and destruction in the atmospheric surface layer, Ibid., 218, 456-457, 1968.

Galbally, I. and Allison, I.: Ozone fluxes over snow surfaces, J. Geophys. Res., 77, 3946-3949, 1972.

Ganzeveld, L. and Lelieveld, J.: Dry deposition parameterization in a chemistry general circulation model and its influence on the distribution of reactive gases, J. Geophys. Res., 100, 2099921012, 1995.

Goulden, M. L., Munger, J. M., Fan, S.-M., Daube, B. C., and Wofsy, S. C.: Measurements of carbon sequestration by longterm eddy covariance: methods and a critical evaluation of accuracy, Glob. Change Biol., 2, 169-182, 1996.

Helmig, D., Bocquet, F., Cohen, L., and Oltmans, S. J.: Ozone uptake to the polar snow at Summit, Greenland, Atmos. Environ., 41, 5061-5076, 2007a.

Helmig, D., Ganzeveld, L., Butler, T., and Oltmans, S. J.: The role of ozone atmosphere-snow gas exchange on polar, boundarylayer tropospheric ozone - a review and sensitivity analysis, Atmos. Chem. Phys., 7, 15-30, doi:10.5194/acp-7-15-2007, 2007b.

Helmig, D., Oltmans, S. J., Carlson, D., Lamarque, J.-F., Jones, A., Labuschagne, C., Anlauf, K., and Hayden, K.: A review of surface ozone in the polar regions, Atmos. Environ., 41, 51385161, 2007c.

Helmig, D., Oltmans, S. J., Morse, T. O., and Dibb, J. E.: What is causing high ozone at Summit, Greenland?, Atmos. Environ., 41, 5031-5043, 2007d.

Helmig, D., Apel, E. C., Balke, D., Ganzeveld, L., Lefer, B., and Swanson, A. L.: Release and uptake of volatile inorganic and organic gases through the deep, winter snowpack at Niwot Ridge, Colorado, Biogeochem., 95, 167-183, 2009a.

Helmig, D., Cohen, L., Bocquet, F., Oltmans, S., Grachev, A., and Neff, W.: Spring and summertime diurnal ozone fluxes over the polar snow at Summit, Greenland, Geophys. Res. Lett., 38, L08809, doi:10.1029/2008GL036549, 2009b.

Helmig, D., Seok, B., Williams, M. W., Hueber, J., and Sanford, R. J.: Fluxes and chemistry of nitrogen oxides in the Niwot Ridge, Colorado, snowpack, Biogeochem., 95, 115-130, 2009c.

Huntzicker, J. J. and Johnson, R. L.: Investigation of an ambient interference in the measurement of ozone by ultraviolet absorption photometry, Environ. Sci. Technol., 13, 1414-1416, 1979.

Kaimal, J. C. and Finnigan, J. J.: Atmospheric boundary layer flows: their structure and measurements, Oxford University Press, New York, Oxford, 289 pp., 1994.

Klaussen, J., Zellweger, C., Buchmann, B., and Hofer, P.: Uncertainty and bias of surface ozone measurements at selected Global Atmosphere Watch sites, J. Geophys. Res., 108, 4622, 
doi:10.1029/2003JD003710, 2003.

Kleindienst, T. E., Hudgens, E. E., Smith, D. F., McElroy, F. F., and Bufalini, J. J.: Comparison of chemiluminescence and ultraviolet ozone monitor responses in the presence of humidity and photochemical pollutants, J. Air Waste Manag. Assoc., 43, 213-222, 1993.

Lamarque, J.-F., Hess, P., Emmons, L., Buja, L., Washington, W., and Granier, C.: Tropospheric ozone evolution between 1890 and 1990, J. Geophys. Res., 110, D08304, doi:10.1029/2004JD005537, 2005.

Neff, W., Helmig, D., Grachev, A., and Davis, D.: A study of boundary layer behavior associated with high NO concentrations at the South Pole using a minisodar, tether balloon, and sonic anemometer, Atmos. Environ., 42, 2762-2779, 2007.

Oke, T. R.: Boundary Layer Climates, 2nd Edn, University Press, Cambridge, 435 pp., 1987.

Oren, R., Hsieh, C.-I., Stoy, P., Albertson, J., McCarty, H. R., Harrell, P., and Katul, G. G.: Estimating the uncertainty in annual net ecosystem carbon exchange: spatial variation in turbulent fluxes and sampling errors in eddy-covariance measurements, Glob. Change Biol., 12, 883-896, 2006.

Pollard, R. T., Rhines, P. B., and Thompson, R.: The deepening of the wind-mixed layer, Geophys. Fluid Dyn., 3, 381-404, 1973.

Regener, V. H.: The vertical flux of atmospheric ozone, J. Geophys. Res., 62, 221-228, 1957.

Reinking, R. F.: The respective effects of water vapor and temperature on the turbulent fluxes of sensible and latent heat, Bound.Layer Meteorol., 19, 373-385, 1980.
Rotman, D. A., Atherton, C. S., Bergmann, D. J., Cameron-Smith, P. J., Chuang, C. C., Connell, P. S., Dignon, J. E., Franz, A., Grant, K. E., Kinnison, D. E., Molenkamp, C. R., Proctor, D. D., and Tannahill, J. R.: IMPACT, the LLNL 3-D global atmospheric chemical transport model for the combined troposphere and stratosphere: Model description and analysis of ozone and other trace gases, J. Geophys. Res., 109, D04303, doi:10.1029/2002JD003155, 2004.

Seok, B., Williams, M. W., Helmig, D., Liptzin, D., Chowanski, K., and Hueber, J.: An automated system for continuous measurements of trace gasfluxes through snow: an evaluation of the gas diffusion method at a subalpine forest site, Niwot Ridge, Colorado, Biogeochem., 95, 95-113, 2009.

Stocker, D. W., Zeller K. F., and Stedman, D. H.: $\mathrm{O}_{3}$ and $\mathrm{NO}_{2}$ Fluxes over snow measured by eddy correlation, Atmos. Environ., 29, 1299-1305, 1995.

Stull, R. B.: An Introduction to Boundary Layer Meteorology, Kluwer Academic Publishers, 666 pp., 1988.

Webb, E. K., Pearman, G. I., and Leuning, R.: Correction of flux measurements for density effects due to heat and water vapor transfer, Q. J. Roy. Meteorol. Soc., 106, 85-100, 1980.

Wilson, K. L. and Birks, J. W.: Mechanism and elimination of a water vapor interference in the measurement of ozone by UV absorbance, Environ. Sci. Technol., 40, 6361-6367, 2006.

Zeller, K. and Hehn, T.: Measurements of upward turbulent ozone fluxes above a subalpine spruce-fir forest, Geophys. Res. Let., 23, 841-844, 1996.

Zeller, K. F. and Nikolov, N. T.: Quantifying simultaneous fluxes of ozone, carbon dioxide and water vapor above a subalpine forest ecosystem, Environ. Pollut., 107, 1-20, 2000. 